\title{
Quantitative Electron Diffraction Data of Amorphous Materials
}

Jürgen Ankele ${ }^{\mathrm{a}}$, Joachim Mayer ${ }^{\mathrm{b}}$, Peter Lamparter $^{\mathrm{c}}$, and Siegfried Steeb ${ }^{\mathrm{c}}$

${ }^{a}$ Alcatel SEL AG, Lorenzstraße 10, D-70435 Stuttgart, Germany

${ }^{\mathrm{b}}$ Rheinisch-Westfälische Technische Hochschule Aachen, Gemeinschaftslabor für

Elektronenmikroskopie, Ahornstraße 55, D-52074 Aachen, Germany

${ }^{c}$ Max-Planck-Institut für Metallforschung, Heisenbergstraße 3, D-70569 Stuttgart, Germany

Reprint requests to Dr. P. L.; Fax: +49 (0)711 689-3312; E-mail: Lamparter@mf.mpg.de

Z. Naturforsch. 60a, $459-468$ (2005); received March 15, 2005

A method has been developed to obtain quantitative electron diffraction data up to a value of $Q=20 \AA^{-1}$ of the modulus of the scattering vector. The experiments were performed on a commercially available transmission electron microscope equipped with a so-called omega energy filter. An analytical multiple scattering correction was applied. The electron diffraction results obtained with amorphous germanium were compared with X-ray and neutron diffraction data and showed good agreement. For an amorphous $\mathrm{Ni}_{63} \mathrm{Nb}_{37}$ sample it was shown that it is possible to estimate the multiple scattering intensity without exact knowledge of the sample thickness. This technique was applied to derive the structure factor for electron diffraction of two precursor-derived amorphous Si-C-N ceramics (a-Si ${ }_{24} \mathrm{C}_{43} \mathrm{~N}_{33}$ and a-Si $\mathrm{Si}_{40} \mathrm{C}_{24} \mathrm{~N}_{36}$ ). The results are consistent with corresponding $\mathrm{X}$-ray diffraction data and with an existing structural model for such ceramics.

Key words: Electron Diffraction; Amorphous Materials; Multiple Scattering Correction. 